Original Research Paper

\title{
Preparedness in Implementing Action Plan for Reducing GHGs: The Case of Central Java
}

\author{
Agung Sugiri \\ Diponegoro University, Semarang, Indonesia
}

Article history

Received: 25-11-2014

Revised: 24-01-2015

Accepted: 25-03-2015

\begin{abstract}
The Regional Action Plan for Reducing Greenhouse Gas Emissions (RAD-GRK) of Central Java Province 2020 was completed in 2012. This paper assesses the preparedness of the Central Java Provincial Government (CJPG) to implement the plan and identifies measures needed to ensure successful implementation based on the stakeholders' perceptions. In-depth interviews with key CJPG officials and a workshop with the extended participants involved in the implementation of the RAD-GRK were conducted. The analysis methods used are content analysis and force-field analysis. The results show that, in general, the CJPG is just slightly better than 'half prepared' (3.47 out of 5). Among the six priority sectors, forestry is the most prepared with 4.01 in the score, means 'prepared but may need some help or adjustment'. It is then followed by waste management (3.75), agriculture (3.67), transportation (3.67), energy (3.59) and manufacturing industry (1.75). Meanwhile, among the five influencing factors, the legal framework is the most prepared (3.74). It is followed by financial (3.46), institutional (3.45), human resource (3.36) and physical and equipment (3.35) factors. Measures needed for successful implementation have also been proposed, for example, additional personnel with suitable and proper capability are needed to implement many programs of the industry sector.
\end{abstract}

Keywords: Climate Change, GHGs Reduction, Implementation, Preparedness, Regional Action Plan

\section{Introduction}

Indonesia is among the countries committed to addressing the climate change problems. The national action plan for Greenhouse Gasses (GHGs) reduction (RAN-GRK in Indonesian acronym) was constructed (PRI, 2011). Afterward, the Regional Action Plan for Reducing Greenhouse Gas Emissions (RAD-GRK) of Central Java Province 2010-2020 was also completed. The plan has been decreed as the Governor Regulation No. 43/2012. This plan focuses on mitigation aspect, the main purpose of which is to reduce GHGs so that environmental damages due to climate change can be reversed, in the long run.

Despite the need to also plan the adaptation, it is not less important that the preparedness of the Central Java Provincial Government (CJPG) in implementing the RAD-GRK be assessed.

As noted by the stakeholders, the drafting process of the plan was somewhat in a rush due to the urgent need of the province. Meanwhile, during the first year of implementation, i.e., 2013, the stakeholders have come to realize that difficulties and flaws have been there. For example, some programs need new computer software's or equipment with the newest technology to achieve the targeted results. Similarly, some other programs require more data. In addition, planning for climate change mitigation should be in the long term, means more than ten years (Travis, 2013). Ten-year period is supposed for adaptation plan (Storch and Winkel, 2013). So, this RAD-GRK will most probably be continued with a long term plan.

Hence, the questions are: "How prepared is the CJPG in ensuring successful implementation of the RADGRK?"; and "What treatments should be done to make the CJPG prepared better for the implementation?". This paper presents the answers to such questions.

Assessing the preparedness of the CJPG would recognize important aspects. First, to what extent the provincial government is prepared to implement the 
RAD-GRK can be identified. It is true that the plan was constructed realistically in the sense that the provincial government's capability to implement it was considered implicitly. It is seen, especially, in the details of locations, responsible institutions and funding sources for every action that is planned. However, careful identification of the position of the CJPG was not part of the plan so that this study is needed. Second, kinds of effort and helps needed by the CJPG to be more prepared can also be identified. Also, when the preparedness level is known, to what extent the CJPG should make efforts to improve its preparedness and what measures should be done for successful implementation of the RAD-GRK can also be realized.

The map of Central Java showing the main roads, railways and administrative boundaries of cities (kota) and regencies (kabupaten) in the region can be seen in Fig. 1.

\section{Objective and Methodology}

This study aims to assess the preparedness of the CJPG in the RAD-GRK implementation and to identify measures needed to ensure successful implementation.

The following part briefly discusses the methodology.

\section{Stage 1: Preparation}

This stage includes preparing the official permits for this project, compiling and studying secondary information such as the Central Java RAD-GRK and the job descriptions of related key CJPG agencies (Dinas, Badan and SKPD).

Stage 2: Assessment of the Preparedness of RADGRK Implementation

- It started with developing a set of propositions, which includes the assessment criteria and preparing forms and guidelines for interviews and discussions with the CJPG key agencies and other relevant stakeholders

- Discussions with the CJPG related key institutions in the form of in-depth interviews with representatives of the key agencies. It could result in the refinement of the propositions. It was then continued with a one-day workshop involving key personnel of the CJPG implementing institutions

- Analysis and findings discussion based on the interviews and the discussion results of the workshop

- It ended with concluding remarks

\section{Literature}

Implementing the RAD-GRK is an additional task for all the stakeholders, including the CJPG. This additional task is of two kinds: (1) New work or program that has never been done before and (2) refinement of the existing work or program.

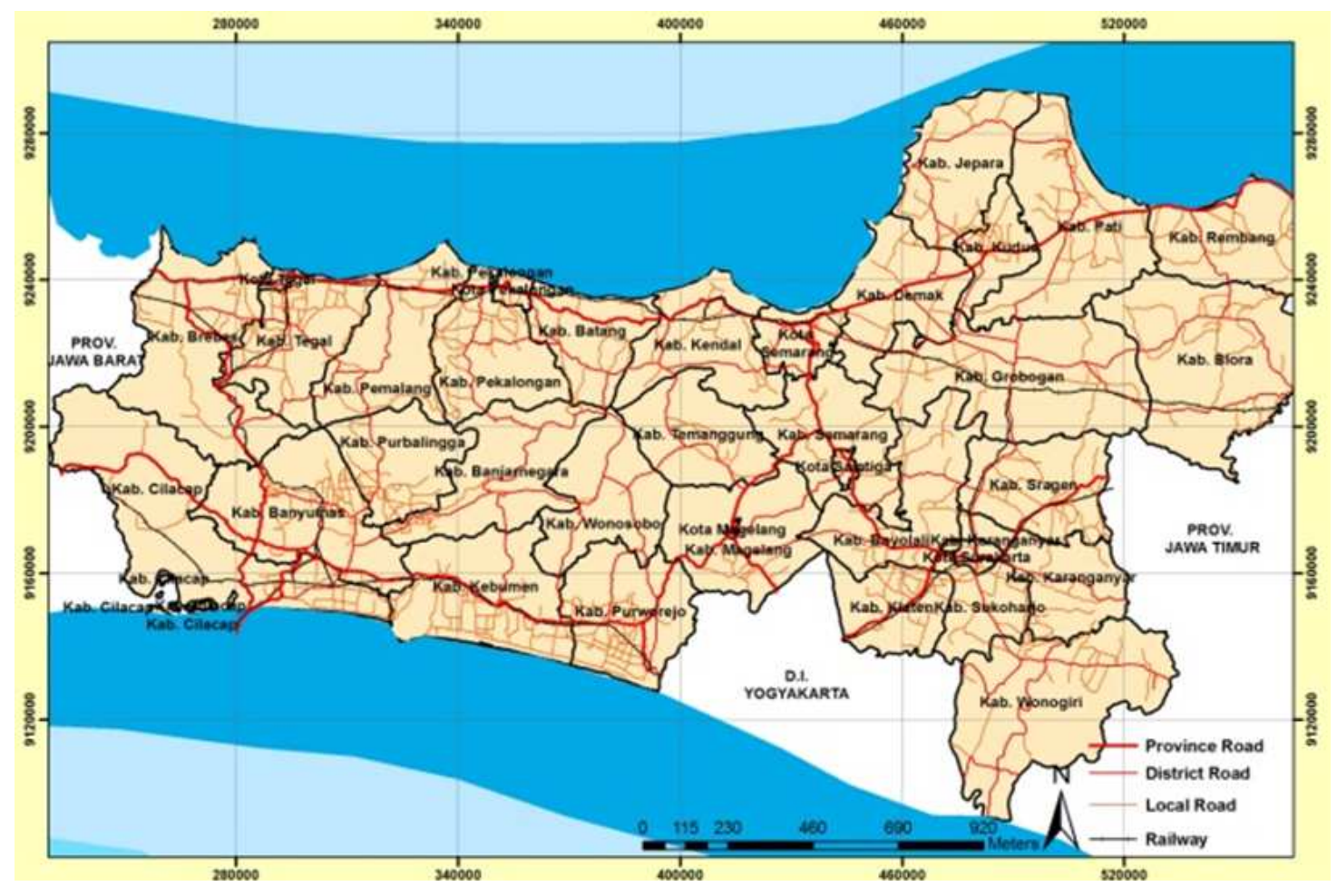

Fig. 1. Map of CENTRAL Java Province, Indonesia 
Although, fortunately, many of the programs seem to be type 2, the refinement can still be viewed as a change that should be dealt with by the CJPG in the future. As a result, assessing the preparedness of CJPG in implementing the RAD-GRK should well consider factors affecting the preparedness for change of the CJPG as a big organization. This section critically reviews the related literature to result in the important factors included in the RAD-GRK preparedness assessment.

\section{Regional Development, Organization and Change}

Central Java Provincial Government can be seen as a regional development organization. An organization is formed to facilitate its elements in achieving certain main aim and objectives. The main aim is usually only one, to achieve an agreed vision. The CJPG vision, for example, is wealthy and integrity for all Central Java population (CJPG, 2014). It would never change. Even if achieved, sustaining the wealth for all will still be the aim.

However, objectives can change over time as prospects and challenges also change. In the initial stage of regional development in developing countries, natural resource exploitation is the best possible way for capital formation (Sugiri, 2009). It would make developing natural resource-based sector as a top priority objective. As the development continues, top priority objective would change into industrial development. Later on, perhaps, poverty alleviation or equitable distribution of development benefits would become the top priority objective. The reason is that the average welfare is already high enough while the economic inequality is deep, as common in the experience of many developing countries with rich natural resource endowment.

Regional development experience of many developing countries has challenged the inverted Ushape rule. The rule says that spatial inequality will deepen in the initial stage of development but will then decrease as the development continues. It has been confirmed by the developed countries' experience. However, the rule is not working in many developing countries, including Indonesia. Sugiri and Nuraini (2013) have found out that alleviating equity failures should be prioritized to ensure more equitable growth in regional development. Thus, addressing the equity failures can be considered a change in certain development objectives and the strategy should also do accordingly.

Any change in the objectives will affect the preparation strategy for coping with it. Inappropriate preparedness will cause failure to achieve the related objectives and the organization would fail as well in achieving the aim. Thus, factors affecting the preparedness of an organization for change should well be understood.

\section{Factors Affecting Organizational Preparedness for} Change

There are various factors that can affect organizational preparedness in coping with change. Arvidsson et al. (2006), for example, have studied the preparedness in applying new technology to the air traffic control organization. They have concluded three factors, i.e., organizational climate, rules/regulation and personnel capability. This study has focused on characteristics of organizational climate affecting the preparedness. Good climate can make the organization well prepared more easily. Accordingly, regulation and personnel capability can be considered as the factors affecting the preparedness of the air traffic control organization.

While Patil and Deepa (2007) have asserted that the negative impacts of climate change causes the poor people and countries suffered the most, Majra and Acharya (2009) conclude that the most influencing factor is knowledge. They investigated the preparedness of medical interns in protecting the population health from climate change impacts in India. It is just logical as, with more knowledge about climate change impacts on health, medical interns will be more prepared for their jobs. This factor is in accordance with personnel capability in Arvidsson et al. (2014) study because better knowledge will contribute to better personnel capability.

In line with this, Ahamed (2013) also gives special emphasis on the importance of knowledge for integrated planning and people empowerment. Ahamed studied the community-based approach for reducing vulnerability to natural hazards, especially cyclone and storm surges in the coastal belt of Bangladesh. He has asserted that rural poor people empowerment, awareness and planning and holistic program approach are the factors affecting the vulnerability reduction efforts. Interestingly, Chowdhury et al. (2011) have come up with two important factors, i.e., social supporting system and community coping capacity. They studied the case of Community Emergency Response Volunteer (CERV) programs in coping with climate change induced communities in Canada. While rural people empowerment, awareness and planning as suggested by Ahamed (2013) can improve the community coping capacity, the holistic program factor is in accordance with improving social support systems.

Another study on community-based adaptation to climate change (van Aalst et al., 2007) has resulted in three factors, i.e., community capability, facilitator capacity and organizational links. As recommended by the study, these factors should be considered in improving the Community Risk Assessments (CRAs) for climate change adaptation at the community level. The factors of community capability and facilitator capacity 
are related each other and can be considered in parallel with the factor of community coping capacity suggested by Chowdhury et al. (2011). Meanwhile, the factor of organizational links is in compliance with the holistic program approach asserted by Ahamed (2013) because successful implementation of such program would certainly need good organizational links.

In the meantime, three factors have been identified. The first is regulation or rules of the game as suggested by Arvidsson et al. (2006). This factor can also be called legal framework factor. The second one is the personnel capability as in Arvidsson et al. (2014) study. This factor encompasses aspects of knowledge (Majra and Acharya 2009; Ahamed, 2013), rural people empowerment (Ahamed, 2013), community coping capacity (Chowdhury et al., 2011) and community and facilitator capacities (van Aalst et al., 2007). In the broader sense of a regional development institution, it can be labeled as human resource factor. The third factor is organizational links (van Aalst et al., 2007) that includes holistic program (Ahamed, 2013) and social support systems (Chowdhury et al., 2011). This factor, in other words, is the institutional factor.

On the other hand, Lwasa (2010) has resulted in five factors, i.e., funding, regulatory and legal frameworks, knowledge, administrative buildings and human and technical capacity. He studied the institutional readiness for adaptation to climate change in the urban areas of Africa using the case of Kampala. Knowledge and human/technical capacity can be included in human resource factor and regulatory and legal frameworks are the same as the legal framework factor. Meanwhile, the factors of funding and administrative buildings can be considered for the case of the CJPG preparedness.

In accordance with this is a study by Lehman et al. (2002) on Organizational Readiness for Change (ORC) using the Texas Christian University as a case. The study has concluded three factors, i.e., leaders and staff capability, institutional resources and physical resources. They are similar to human resource factor, institutional factor and buildings factor consecutively.

Also, Casey et al. (2012) when studying the readiness of State Sporting Organisations (SSOs) to implement health promotion programs in Victoria, Australia, have concluded five factors. They are capacity building, institutional, facility, financial allocation and government policy factors. As recognized, capacity building is part of human resource factor while facility is aligned with buildings factor and government policy is part of legal framework factor. So, all the five factors are in accordance with the whole discussion.

Meanwhile, Valkila and Saari (2012) have concluded three important factors, i.e., reduction in GHG emissions and energy consumption, financial investment and infrastructure capability. They studied about the readiness of the Finland people to behave more environmentally friendly. While the first factor is the RAD-GRK main aim, financial investment can be considered the same as funding factor and infrastructure capability is similar to the factor of buildings and equipment.

Nevertheless, Ramsay (2004) has reminded an important factor that is most forgotten in studies on the organizational preparedness for change, i.e., the spiritual factor. Spiritual preparedness in disaster management, as asserted by Ramsay, is hardly studied. Here, spiritual is in its broad sense, i.e., the internal aspect of humanity, not only in the sense of a certain religion. This factor can make a difference between preparedness and readiness. Members of a community can be well prepared for coping with change; however, they may not be ready for it. Readiness means something more than preparedness. When all plans could not work as expected, a ready community can still cope with the failure better than a prepared one. The spiritual factor, as suggested by Ramsay, could be the key. However, Ramsay's idea has not come into operational yet and that is why readiness and preparedness are still used interchangeably as far as the organizational preparedness for change is concerned.

Finally, five factors affecting preparedness of a regional development organization for change can be concluded and will be used in assessing the CJPG preparedness in implementing the RAD-GRK. These are human resource factor, institutional factor, financial (funding) factor, physical and equipment (buildings and infrastructure) factor and legal framework factor.

\section{Methods}

The approach is a mix of quantitative and qualitative approaches as the inquiry is based on pragmatism worldview (Creswell, 2009). The preparedness level should be approached quantitatively so that the gap can be made clear. However, the conclusion of $20 \%$ gap, for example, may mean nothing without knowing why the flaw occurs and what treatment should be recommended to fill in the gap. It is in this respect that the qualitative approach is essential.

In both approaches, however, assessment should be based on the stakeholders' constructs. The reason is that the stakeholders, i.e., representatives or key persons of the CJPG key institutions, are those who know the most about their potentials and limitations in implementing the RAD-GRK. The quantitative information was collected in a one-day workshop initialized by a half-day meeting. Meanwhile, the qualitative data collection is through in-depth interviews with eight representatives of seven key institutions of the CJPG.

\section{Qualitative Approach}

Qualitative approach was the first done in this study. The main reason is that important results from 
this approach may modify the design of the quantitative one. Interview is the method applied for getting the information. The interviews involved eight key persons from seven key institutions in the CJPG. The key institutions are those involved in the RADGRK planning process and are also the main stakeholders in the implementation, as follows:

- Badan Perencanaan Pembangunan Daerah (Bappeda) Jawa Tengah (Central Java Development Planning Board); one key person was interviewed on June 27, 2013

- Dinas Energi dan Sumber Daya Mineral (ESDM) Jawa Tengah (Central Java Agency of Energy and Mineral Resources); one key person was interviewed on June 28, 2013

- Dinas Kehutanan (Dishut) Jawa Tengah (Forest Management Agency of Central Java); due to the request of the agency, two key persons were interviewed on July 1, 2013

- Dinas Perindustrian dan Perdagangan (Disperindag) Jawa Tengah (Industry and Trade Agency of Central Java); one key person was interviewed on July 1, 2013

- Dinas Pertanian (Distan) Jawa Tengah (Agriculture Development Agency of Central Java); one key person was interviewed on July 3, 2013

- Dinas Perhubungan dan Kominfo (Dishub) Jawa Tengah (Central Java Agency of Transportation, Communication and Information); one key person was interviewed on July 3, 2013

- Badan Lingkungan Hidup (BLH) Jawa Tengah (Environmental Management Board of Central Java); one key person was interviewed on July 8, 2013

Four aspects are the focus of the interview. The first is on how the interviewee perceives the preparedness of her/his institution to implement the RAD-GRK. The second aspect is about factors affecting the CJPG preparedness, whether the stakeholders agree with all the proposed five factors or they think of other factors. The third one is on the preparedness of the RAD-GRK, the results of which are beyond the scope of this paper. Finally, the fourth one is on how to integrate the RAD-GRK into the existing planning and development mechanisms.

Every perception is important and all the constructs are wrapped up using content analysis method. However, the gap between full preparedness and the existing situation should be made clear for decision-making purposes and for this, quantitative approach can help.

\section{Quantitative Approach}

Quantitative approach has the main benefit of identifying the preparedness levels. The stakeholders' constructs on this matter were obtained through the five forms that were filled in by representatives of the related CJPG institutions in a one-day workshop. The representatives were officially appointed by their respective institutions to participate in the workshop. So, although this study has not applied any random sampling method, the representativeness of the population is assured.

In preparing the one-day workshop, a preceding half-day meeting with the workshop participants was conducted. It was to discuss the findings of qualitative investigation and to prepare the workshop participants in filling in the forms. The five forms are based on the force-field framework as seen in the following tables.

The preparedness score is on the scale of one to five with the following meanings:

- 1: Unprepared with no prospect at all

- 2: Unprepared but with some prospect

- 3: A fifty-fifty situation or half prepared

- 4 : It is considered prepared but may need some help or adjustment

- $\quad$ : It is considered fully prepared; no need any help or adjustment

As seen in the below forms (Table 1 to 5), constructs that are qualitative in nature are also accommodated. This way would complement the results of the in-depth interviews.

\section{Findings and Discussion}

It is hard to find similar studies published in peerreviewed journals. Many of the related studies are on the preparedness for climate change, especially on the adaptation aspects. For this reason, it is with this kind of recent studies that the research's findings, especially in the measures proposed, are discussed.

Table 1. Form of preparedness score table (existing situation)

\begin{tabular}{|c|c|c|c|c|c|c|c|}
\hline \multirow[b]{2}{*}{ No. } & \multicolumn{2}{|c|}{ RAD-GRK action program } & \multicolumn{5}{|c|}{ Preparedness factors } \\
\hline & New & Refinement & Human resource & Institutional & Financial & Physical and equipment & Legal framework \\
\hline 1 & $X$ & & score & score & score & score & score \\
\hline 2 & & $\mathrm{X}$ & score & score & score & score & score \\
\hline$\cdots$ & $X$ & & $\begin{array}{l}\ldots \\
\text { score }\end{array}$ & $\begin{array}{l}\ldots \\
\text { score }\end{array}$ & $\begin{array}{l}\ldots \\
\text { score }\end{array}$ & $\begin{array}{l}\ldots \\
\text { score }\end{array}$ & $\begin{array}{l}\ldots \\
\text { score }\end{array}$ \\
\hline
\end{tabular}


Table 2. Form of encouraging forces

\begin{tabular}{|c|c|c|c|c|c|c|c|}
\hline \multirow[b]{2}{*}{ No. } & \multicolumn{2}{|c|}{ RAD-GRK action program } & \multicolumn{5}{|c|}{ Preparedness factors } \\
\hline & New & Refinement & Human resource & Institutional & Financial & Physical and equipment & Legal framework \\
\hline 1 & $\mathrm{X}$ & & description & description & description & description & description \\
\hline 2 & & $\mathrm{X}$ & description & description & description & description & description \\
\hline$\cdots$ & $X$ & & $\begin{array}{l}\ldots \\
\text { description }\end{array}$ & $\begin{array}{l}\ldots \\
\text { description }\end{array}$ & $\begin{array}{l}\ldots \\
\text { description }\end{array}$ & $\begin{array}{l}\ldots \\
\text { description }\end{array}$ & $\begin{array}{l}\ldots \\
\text { description }\end{array}$ \\
\hline
\end{tabular}

Table 3. Form of obstructing forces

\begin{tabular}{|c|c|c|c|c|c|c|c|}
\hline \multirow[t]{2}{*}{ No. } & \multicolumn{2}{|c|}{ RAD-GRK action program } & \multicolumn{5}{|c|}{ Preparedness factors } \\
\hline & New & Refinement & Human resource & Institutional & Financial & Physical and equipment & Legal framework \\
\hline $\begin{array}{l}1 \\
2\end{array}$ & $\mathrm{X}$ & $X$ & $\begin{array}{l}\text { description } \\
\text { description }\end{array}$ & $\begin{array}{l}\text { description } \\
\text { description }\end{array}$ & $\begin{array}{l}\text { description } \\
\text { description }\end{array}$ & $\begin{array}{l}\text { description } \\
\text { description }\end{array}$ & $\begin{array}{l}\text { description } \\
\text { description }\end{array}$ \\
\hline $\begin{array}{l}\cdots \\
\mathrm{n}\end{array}$ & $X$ & & $\begin{array}{l}\ldots \\
\text { description }\end{array}$ & $\begin{array}{l}\ldots \\
\text { description }\end{array}$ & $\begin{array}{l}\ldots \\
\text { description }\end{array}$ & $\begin{array}{l}\ldots \\
\text { description }\end{array}$ & $\begin{array}{l}\ldots \\
\text { description }\end{array}$ \\
\hline
\end{tabular}

Table 4. Form of reasonable targets for 2015

\begin{tabular}{|c|c|c|c|c|c|c|c|}
\hline \multirow[b]{2}{*}{ No. } & \multicolumn{2}{|c|}{ RAD-GRK action program } & \multicolumn{5}{|c|}{ Preparedness targets } \\
\hline & New & Refinement & Human resource & Institutional & Financial & Physical and equipment & Legal framework \\
\hline 1 & $\mathrm{X}$ & & score & score & score & score & score \\
\hline 2 & & $\mathrm{X}$ & score & score & score & score & score \\
\hline$\cdots$ & & & $\cdots$ & $\cdots$ & $\cdots$ & $\cdots$ & $\cdots$ \\
\hline $\mathrm{n}$ & X & & score & score & score & score & score \\
\hline
\end{tabular}

Table 5. Form of treatments needed

\begin{tabular}{|c|c|c|c|c|c|c|c|}
\hline \multirow[b]{2}{*}{ No. } & \multicolumn{2}{|c|}{ RAD-GRK action program } & \multicolumn{5}{|c|}{ Preparedness factors } \\
\hline & New & Refinement & Human resource & Institutional & Financial & Physical and equipment & Legal framework \\
\hline $\begin{array}{l}1 \\
2\end{array}$ & $\mathrm{X}$ & $X$ & $\begin{array}{l}\text { description } \\
\text { description }\end{array}$ & $\begin{array}{l}\text { description } \\
\text { description }\end{array}$ & $\begin{array}{l}\text { description } \\
\text { description }\end{array}$ & $\begin{array}{l}\text { description } \\
\text { description }\end{array}$ & $\begin{array}{l}\text { description } \\
\text { description }\end{array}$ \\
\hline $\begin{array}{l}\cdots \\
\mathrm{n}\end{array}$ & $\mathrm{X}$ & & $\begin{array}{l}\ldots \\
\text { description }\end{array}$ & $\begin{array}{l}\ldots \\
\text { description }\end{array}$ & $\begin{array}{l}\ldots \\
\text { description }\end{array}$ & $\begin{array}{l}\ldots \\
\text { description }\end{array}$ & $\begin{array}{l}\ldots \\
\text { description }\end{array}$ \\
\hline
\end{tabular}

\section{Constructs Resulted from the Interviews}

In general, many of the key persons perceive that the CJPG is prepared for the RAD-GRK implementation, because most of the programs planned are those that have been being done routinely. It means that what the CJPG needs is mostly a refinement of its daily work to achieve the target of $11.29 \%$ decrease in GHG emissions in 2020 (CJPG, 2012).

However, opposing perception is not less important as particularity is one of the keywords in qualitative analysis, especially from the social constructivism viewpoint. Disperindag and, to a lesser extent, Dishut and ESDM key persons have expressed this opinion. The key person from Disperindag, for example, believes that her institution is not prepared yet. She argues that many of Disperindag's proposed programs could not be accommodated in the RAD-GRK due to the very short time of its formulation.

Meanwhile, Dishut's key persons have stated that the institution is making every effort possible to prepare for the RAD-GRK implementation. However, they realize that many programs are under the authority of City/Regency (Kota/Kabupaten) governments. What their institution can do, so far, is some capacity building for the City/Regency staff. So, it is apparent that the Dishut is somewhat not fully prepared yet.

On the other hand, ESDM key person has expressed another flaw. Although he is quite sure that his institution is prepared enough, he is still not certain about the contribution of every program in reducing GHG emissions. He is rather regretful that his institution was not fully involved in formulating the measurement methods and counting the GHG reductions.

Below is a discussion of constructs of the key persons on each of the preparedness factors, which they have agreed upon the five factors resulted from the literature review.

\section{Human Resource Factor}

Bappeda of Central Java perceives that the institution is fully prepared with its human resource capability and 
capacity to implement the RAD-GRK. The reason is that many programs are those already implemented in the CJPG routine jobs. Dishub is of the opinion that this institution is prepared as well; however, the key person highlights the importance of capacity building for the City/Regency staff. It is because their role is crucial, especially in supplying data and information for the monitoring and evaluation process. On the other hand, Distan gives an important emphasis that the GHG reduction issue is still new for many of the staff. That is why more socialization and capacity buildings are most probably needed.

Other key agencies recognize that their preparedness in human resource is not good enough. BLH emphasizes the lack of officers dealing with the GHG issues, with some of them are still not familiar with the measurement methods. The BLH key person is regretful with the zero-growth policy on recruiting government officers, which makes new staff recruitment is almost impossible. ESDM also has a similar problem as many of the related officers are retiring soon while regeneration process is not as expected. Dishut also faces this problem. The Dishut key persons even feel the lack of officers with the proper expertise in GHG-related jobs. On the other hand, Disperindag draws attention to the lack of capability instead of quantity of its officers. The Disperindag key person proposes the continuation of facilitation and mentoring from German Development Cooperation (GIZ).

ESDM experiences another flaw in human resource factor through the so-called routine rotation that is often nonbeneficial for GHG reduction purposes. In many cases, officers who have already tuned in with the GHGrelated jobs are relocated to do other jobs.

The treatment needed to be more prepared is quality and quantity improvement through capacity buildings and new recruitment. It is in accordance with some literature about climate preparedness. Anguelovski et al. (2014), for example, propose learning, awareness and capacity building for this factor. Capacity building is also proposed by Stone (2014; Rodriguez et al., 2014; Biagini et al., 2014). So, capacity building is something in common for better preparedness.

However, sustained involvement from all stakeholders as proposed by Anguelovski et al. (2014) has not come up from the interviews although this measure seems to be common as well. Also, sense of community (Prior and Eriksen, 2013) and improvement in community social capital (Bihari and Ryan, 2012) are not among the measures proposed. The reason is perhaps that of the difference in focus between adaptation and mitigation.

\section{Institutional Factor}

In this factor, all key persons are of the same opinion that, in general, everything has been fine and would be so for the implementation of the RAD-GRK.
Bappeda, however, has highlighted an important obstructing potential in the authority aspect. Actions that need big investment like developing final waste disposal systems, big manufacturing industries and big power plants are under the national authority that makes the province unable to control. Somewhat similar perception is also expressed by ESDM in assessing the process of capacity building for the RADGRK implementation. Coordination with the national authority of the RAN-GRK was somewhat not as smooth as expected because once the ESDM was rejected to involve in an important capacity building event although it was initially invited. In addition, Dishut underlines the importance of related capacity buildings for City/Regency staff and that the national authority should help more in facilitating them as the CJPG may not have enough personnel for the purpose.

By and large, better cooperation with national and local authorities is the proposed measure. This measure is similar with collective problem-solving proposed in the study of wildfire preparedness by Prior and Eriksen (2013). On the other hand, innovative management, as suggested by Stone (2014; Rodriguez et al., 2014; Biagini et al., 2014), is not proposed in the interviews. The difference in characteristics between this study's interviewees and those studies' respondents is perhaps the reason for this.

\section{Financial Factor}

From the CJPG viewpoint, all key persons are optimistic that external help may not be needed. However, Bappeda perceives that big fund is of the national authority and so it should be distributed equitably to help the achievement of provincial targets for GHGs reduction. Disperindag has expressed similar voice highlighting the importance of facilitation and mentoring from the national authority.

Other agencies are also quite optimistic with the funding available in the CJPG annual budgeting. BLH is even practicing an innovative mechanism, within the existing legal framework, to facilitate City/Regency governmental staff in ensuring the achievement of the RAD-GRK targets. However, BLH also admits that the fund available for this purpose is limited. So, innovative measures should be taken to utilize national and City/Regency funds more effectively.

Meanwhile, when cross-checked with the need to improve the physical and equipment factor, Dishut and Dishub reveal the lack of important equipment as seen in the succeeding discussion. Improvement in this factor, of course, will need additional funds that the CJPG could not afford and needs help from the national and city/regency authorities.

So, the main measure of this factor (financial help from the national and city/regency governments) is 
perhaps quite locally specific. However, it is comparable with new investments proposed by Stone (2014) in preparedness for drought events and Rodriguez et al. (2014) in participatory climate preparedness for Australia.

\section{Physical and Equipment Factor}

In general, there would be no big problem with the physical and equipment factor. However, Dishut and Dishub have important notes on aspects that should be improved immediately.

The key persons of Dishut emphasize the importance of satellite images in GHG-related analysis. The national authority renews the satellite images every three years and this is considered not good enough. Dishut deems that renewals should be on an annual basis to catch up with the need for accurate information on the monitoring and evaluation processes.

Similarly, Dishub highlights the need to improve the equipment for Area Traffic Control System (ATCS) for both the provincial and city/regency authorities. Some cities/regencies, like Surakarta City, for example, already have proper ATCS. However, as data from every City/Regency traffic counting are important, Dishub urges that every City/Regency in Central Java be equipped with appropriate ATCS.

New technology and additional equipment are two measures proposed for this factor. They are similar to those recommended by Stone (2014; Rodriguez et al., 2014; Biagini et al., 2014). Those are new technology, innovative farming systems and information and communications technology as well as improved infrastructure respectively.

\section{Legal Framework Factor}

In this factor, all key persons are of the same opinion that, in general, the legal framework is prepared for the RAD-GRK implementation.

However, Bappeda notifies that some refinement of the authority aspect should be made, especially for many programs in the industry sector that are currently managed by the national authority. Perhaps, better coordination to accommodate more control by the provincial government should be arranged and this should be within the national legal framework. Meanwhile, Dishub prompts the importance of certain supporting programs in the RADGRK that would need refinement of the provincial legal framework, such as the car-free-day program.

Overall, the interviewees propose new regulations and better enforcement of the existing ones as the measures for better preparedness. These treatments are in line with new policies and policy reform recommended by Stone (2014) and Biagini et al. (2014) respectively.

\section{Constructs Resulted from the Workshop}

\section{The Existing Preparedness}

Overall, the existing preparedness level of the CJPG is at the score of 3.47, as seen in Table 6 and Fig. 2. It means that the CJPG is just slightly better than half prepared and would need some help and adjustment. It is consistent with the construct expressed through the interviews.

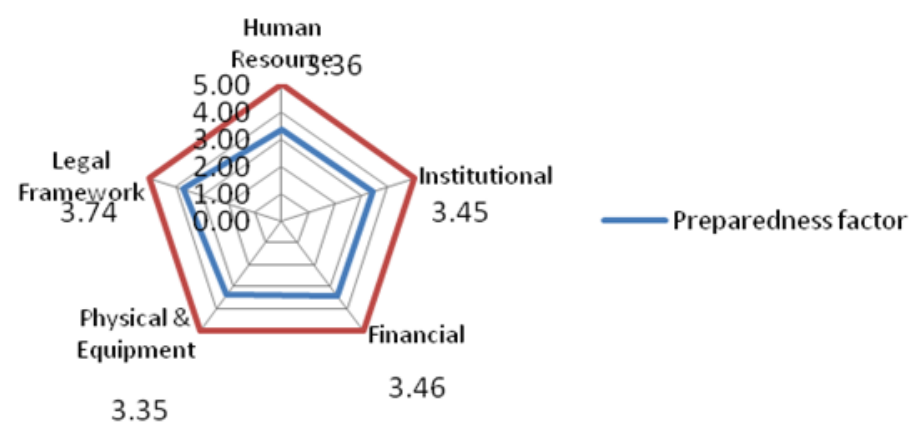

Fig. 2. The existing preparedness of the CJPG to implement RAD-GRK

Table 6. The Existing Preparedness Scores of the CJPG to Implement RAD-GRK

\begin{tabular}{|c|c|c|c|c|c|c|}
\hline \multirow[b]{2}{*}{ Sector } & \multicolumn{5}{|l|}{ Factor } & \multirow[b]{2}{*}{ Average } \\
\hline & $\begin{array}{l}\text { Human } \\
\text { resource }\end{array}$ & Institutional & Financial & $\begin{array}{l}\text { Physical and } \\
\text { equipment }\end{array}$ & $\begin{array}{l}\text { Legal } \\
\text { framework }\end{array}$ & \\
\hline Agriculture & 4.00 & 4.00 & 3.33 & 3.33 & 3.67 & 3.67 \\
\hline Forestry & 4.00 & 4.00 & 4.00 & 4.04 & 3.99 & 4.01 \\
\hline Energy & 3.69 & 3.73 & 3.53 & 3.40 & 3.60 & 3.59 \\
\hline Transport & 3.80 & 4.20 & 3.40 & 3.40 & 3.53 & 3.67 \\
\hline Manufacturing industry & 1.00 & 1.00 & 3.00 & 2.00 & - & 1.75 \\
\hline Waste & 3.66 & 3.78 & 3.47 & 3.94 & 3.91 & 3.75 \\
\hline Average & 3.36 & 3.45 & 3.46 & 3.35 & 3.74 & 3.47 \\
\hline
\end{tabular}


Interestingly, as mentioned, the one-day workshop participants were representatives of all CJPG implementing agencies while the interviewees were representatives of the seven key agencies only. So, any consistency of construct could mean that the construct is the whole stakeholders' one.

It is also obvious that the gap from the ideal situation of fully prepared is, on average, significant. When each factor is considered individually, the deepest gaps, around 1.6 points, are there for the human resource and physical and equipment factors. The least, but still significant, gap is around 1.2 points for the legal framework factor. The factors of human resource and physical and equipment should thus be in high priority.

When each of the six sectors is considered separately, the manufacturing industry shows alarming results. The sector is under the responsibility of mostly Disperindag and, to some extent, Biro Bina Produksi and BLH. As seen in Table 6, the scores for the five factors are significantly lower than those of the others while the sector's average preparedness is also the worst, 1.75 . It is somewhat consistent with the interview results. Also, the stakeholders of this sector could not achieve an agreement to fill in the score of legal framework factor. No arguments were there, so it should be considered abstain in computing the average score.

\section{Encouraging and Obstructing Forces}

\section{Industry Sector}

As mentioned, the manufacturing industry sector is the most crucial one. It is unfortunate that there are no encouraging forces mentioned by the stakeholders of this sector.

In the human resource factor, the obstructing force is the improper capacity and capability of the staff dealing with the programs. Meanwhile, many programs are not within the authority of Disperindag. They are the jobs of the national authority. It is the main obstructing force for the institutional factor. This finding is similar with that of the interview. Another obstructing force is the problem of intra- and inter-agency coordination.

In the physical and equipment, the main obstructing force is the lack of equipment, especially for the needs to apply high technology. It is not surprising then that the limitation of budget available in the existing scheme is considered the main obstructing force for the financial factor.

\section{Energy Sector}

In the physical and equipment factor, the main encouraging force is that Central Java has the promising capability to implement the programs successfully. The province's high potential of geothermal sources is an example. Meanwhile, in the human resource factor, it is encouraging that the number of staff is sufficient.
However, the improper competence of many of them, which is partly due to the inappropriate staff rotation system, is obstructing.

As for the institutional factor, the main encouraging force is that the jobs are routine in nature so that what needed is a refinement. Another is the involvement of private sector as happened in the program of developing geothermal power plants. On the other hand, there are two obstructing forces. The first is that the institutional capability may not be sufficient to audit so many industries in Central Java, as in the program of energy auditing. Meanwhile, low competitiveness due to the high prices of bio-fuels may hamper the prospect of public-private partnerships in the program of developing bio-fuel production.

In the financial factor, the first encouraging force is the availability of sufficient domestic fund. The second is in terms of financial benefits expected from the projects in certain programs, as in the program of developing geothermal power plants. On the other hand, the obstructing force is the need of external funding, especially for programs with big investments.

As for the legal framework factor, the main encouraging force is the availability of proper legal support for many programs. However, two obstructing forces are there. First, certain rules need more socialization. Second, some important programs are not equipped yet with proper legal frameworks.

\section{Agriculture Sector}

In the human resource factor, the encouraging force is the proper personnel competence because many of the RAD-GRK jobs are routine. On the other hand, the obstructing force is the quantity of personnel that may need some more, especially for the refinement purposes.

About the institutional factor, the implementation of some programs needs improved coordination with other stakeholders, especially the private sector and farmers, as in the program of increasing the use of organic and biomass fertilizers. Meanwhile, in the financial factor, the availability of the provincial budget is encouraging. However, some programs still need additional funding from the national budget, as in the program of increasing the use of organic and biomass fertilizers.

In the physical and equipment factor, the existing equipment is considered enough for the minimum function. So, improving the performance of the programs would need additional equipment. For example, to develop low emission rice variety would need more equipment for the seeding activity.

Finally, the main encouraging force for the legal framework is that rules of the game are available, along with proper coordination practices. However, in many programs, the corresponding rules are still in the form of suggestion from the authorities, which is obstructing. 


\section{Transportation Sector}

In this sector, obstructing force is even there for the most prepared factor, the institutional factor, i.e., the improper inter-agency coordination. Fortunately, the main encouraging force is that the corresponding agency (Dishub) is prepared as the coordinator of the programs implementation.

Meanwhile, for the human resource factor, the main encouraging force is the availability of personnel with proper capability. However, the main obstructing force is that many of the proper personnel will be retiring soon while the regeneration process is not as expected. Also, the lack of proper personnel for implementing some programs with high technology is obstructing, as in the programs of developing Intelligent Transport System (ITS) and reforming the Transit System.

As for the legal framework, the availability of laws (undang-undang) and other rules in the existing legal system is the main encouraging force. On the other hand, the vacuum of provincial regulations (perda) for some programs, like for the programs of developing ITS, TIC and parking management, is obstructing.

Meanwhile, there are two encouraging forces for the financial factor, i.e., the availability of the Provincial Budget (APBD) and the commitment to finance the implementation of the programs. On the other hand, there are three obstructing forces. The first is that the available fund from APBD is considered not enough in many programs. The second is that in some programs, there is no commitment made in the provincial budget. The third one is the lack of funding from the main third parties responsible for the implementation of some programs, as in the program of vehicle renewals for public transportation.

For the physical and equipment factor, three encouraging forces are there. The first is that buildings and equipment are available. Second, the commitment to equipment improvement is there. The third is that third parties to help with the need of equipment are also existent. On the other hand, there are two obstructing forces identified. The first is the lack of equipment quantitatively and qualitatively as found in, for example, the programs of vehicle renewals for public transport and smart driving training and socialization. The second is the underutilization of the available and proper equipment.

\section{Waste Management Sector}

In the physical and equipment factor, the first encouraging force is the availability of buildings and equipment. The second is the commitment from the CJPG for additional equipment and technology improvement. Third, the improvement of buildings, equipment and the technology is on-going in some programs. However, obstructing forces are also there in terms of insufficient equipment and less advanced technology in some programs, as in the programs of developing sanitary landfill system and controlled landfill system for the final waste-disposal sites.

For the legal framework factor, the main encouraging force is that the rules are already there in terms of laws and national as well as local regulations. However, obstructing forces are in terms of the sub-optimal law enforcement as found in many programs and the unclearness of the rules as found in the programs of developing eco-sanitation and coastal cleaning up.

For the institutional factor, provincial institutions dealing with the jobs, including the new ones, are already available, as in the program of developing composting facilities in the waste disposal sites. Other encouraging forces are there in terms of the fine coordination of the regular programs and that initiations have been made properly both for the new and refinement jobs. However, obstructing forces are there. First, the involving institutions are so many that make the coordination is not easy. Second, many corresponding institutions in city and regency governments are not ready yet, as in the programs of closing the open dumping sites and utilizing landfill gas as an alternative source of energy. The third is the low effectiveness of the supervision function as found in the program of developing composting facilities in the waste disposal sites. Finally, the difficulty, in involving the private sector and communities in partnership schemes, is also obstructing.

For the human resource factor, the first encouraging force is the availability of sufficient personnel with proper capability. The second is the availability of young personnel with opportunities for capacity building as found in the facilitation program of plastic waste recycling. On the other hand, obstructing forces are in terms of two kinds as well. The first is about the personnel's capability that needs improvement. The second is the lack of personnel, as in the program of developing sanitary landfill systems and the program of community institutional strengthening for waste management.

Finally, for the financial factor, the first encouraging force is the funding availability from the provincial budget and commitment by the CJPG for additional fund in the future. The second is about the opportunities to get help from other parties as found in the program of developing environmentally friendly culture and awareness. However, obstructing forces are also there. First, the fund from the provincial budget is often insufficient for some programs. Second, funding has not been committed by local governments as found in the programs of closing the open dumping sites and utilizing landfill gas as an alternative source of energy. 


\section{Forestry Sector}

It is the most prepared sector. For the human resource factor, the main encouraging force is the availability of key personnel with proper skills. On the other hand, the quantity and quality of personnel as a whole are considered sub-optimal. It is obstructing and found in many programs.

As for the institutional factor, the main encouraging force is that sections in the main institutions (Forestry Agency and Plantation Agency) needed for implementing the programs are there. Also, cooperation with other institutions and communities in some programs have so far been good. However, the main obstructing force is about the sub-optimal performance of the existing work. Another obstructing force is that cooperation with other parties is still not fully satisfying in some programs. The programs of implementing horticulture technology and of crop enrichment are just two examples.

For the financial factor, the main encouraging force in some programs is the availability of funding from either the provincial budget, the national budget, the state enterprises or all of them. However, in many programs, the fund available is still considered limited and insufficient.

As for the physical and equipment factor, the first encouraging force is the availability of buildings and equipment. The second is that third parties are there to help, as in the programs of plant seed facilitation and river catchment management. Conversely, the main obstructing force is the insufficiency of the equipment in implementing many programs. In the program of rehabilitating critical land in priority river catchment areas, for example, the Forestry Agency has experienced data lacking and it is difficult to complete the data using the existing equipment.

Finally, in the legal framework factor, the sole encouraging force is the availability of rules concerning the programs. However, the fact that the rules change rather frequently is considered obstructing.

\section{Reasonable Targets of Preparedness for 2015}

Having known the existing situation of preparedness, as well as the encouraging and obstructing forces, the stakeholders have then defined reasonable targets for 2015 preparedness in every program and each factor. Fig. 3 and Table 7 summarize the targets.

The background on why the year 2015 was chosen is because the representatives of stakeholders could not estimate on what year their institutions will be at full preparedness. That is why the second alternative, to estimate on what level of preparedness their institutions would be for the agreed year, 2015, was chosen.

The overall preparedness score targeted for 2015 is 4.10 while the existing situation is 3.47 . With only about 0.6 point of improvement in around one and a half years, it seems that the CJPG is not too optimistic. The gap of this targeted situation from fully prepared is still at one point, which is significant especially when considering that the RAD-GRK targets should be achieved in only five-year period from 2015.

However, the less optimistic scenario is somewhat understandable. With only around one year left to improve the preparedness while also implementing the RAD-GRK programs, a full preparedness level would be hard to expect. Besides, they should estimate the preparedness score of every program by every factor, which was not an easy task apparently.

\section{Treatments Needed}

Discussion on treatments needed to increase the preparedness level follows the order of the sectors from the lowest to the highest existing preparedness.

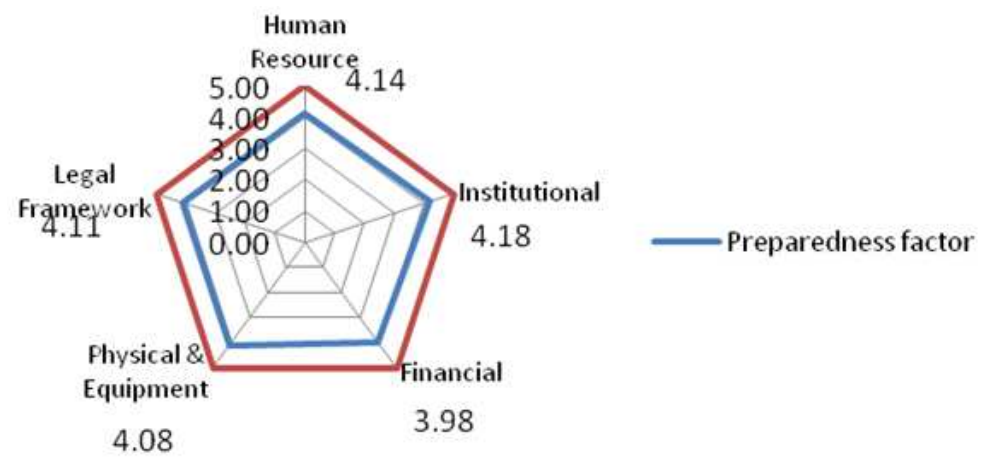

Fig. 3. Reasonable targets for 2015 CJPG preparedness for RAD-GRK implementation 
Table 7. Reasonable Targets for 2015 CJPG Preparedness for RAD-GRK Implementation

\begin{tabular}{|c|c|c|c|c|c|c|c|}
\hline \multirow[b]{2}{*}{ Sector } & \multicolumn{5}{|l|}{ Factor } & \multirow[b]{2}{*}{ Average } & \multirow[b]{2}{*}{ Improvement } \\
\hline & $\begin{array}{l}\text { Human } \\
\text { resource }\end{array}$ & Institutional & Financial & $\begin{array}{l}\text { Physical and } \\
\text { equipment }\end{array}$ & $\begin{array}{l}\text { Legal } \\
\text { framework }\end{array}$ & & \\
\hline Agriculture & 4.00 & 4.00 & 3.64 & 3.86 & 4.00 & 3.90 & 0.23 \\
\hline Forestry & 3.99 & 4.00 & 4.00 & 4.00 & 4.00 & 4.00 & -0.01 \\
\hline Energy & 4.00 & 4.00 & 4.00 & 4.00 & 4.00 & 4.00 & 0.41 \\
\hline Transport & 4.93 & 5.00 & 4.33 & 4.33 & 4.53 & 4.63 & 0.96 \\
\hline Manufacturing Industry & 3.73 & 3.80 & 3.80 & - & - & 3.78 & 2.03 \\
\hline Waste & 4.13 & 4.25 & 4.10 & 4.22 & 4.03 & 4.15 & 0.40 \\
\hline Average & 4.14 & 4.18 & 3.98 & 4.08 & 4.11 & 4.10 & 0.63 \\
\hline
\end{tabular}

\section{Industry Sector}

As the least prepared sector, the treatments needed should be considered more intense, although some of them are, perhaps, of the same kinds as in other sectors.

For the human resource factor, the treatments are consistent with the encouraging and obstructing forces discussed previously. The first is the need of additional personnel with suitable and proper capability as found in, for example, the program of facilitating and giving incentives for the application of low carbon technology. The second is the need to improve the personnel's skills through capacity buildings as found in many programs.

For the institutional factor, consistency on proposing treatments is not as apparent. One of the measures is the same as that for the human resource factor, i.e., capacity buildings. The other one is strengthening commitments from the involving institutions, as in the program of facilitating and giving incentives for the application of low carbon technology. However, this treatment may need further elaboration to be applicable.

Meanwhile, financial help is the sole treatment for the financial factor. It is there in four programs, for example, in the programs of facilitating and giving incentives for the application of low carbon technology and energy conservation and auditing.

About the physical and equipment factor, this sector has not proposed any treatment. It is inconsistent because this sector needs more efforts than any other sector in the RAD-GRK implementation. The foremost one would be the need to improve the availability of equipment both quantitatively and qualitatively. Surprisingly, it has not come up as well from the interview.

On the other hand, although the industry sector has also not scored for the legal framework factor, this sector has proposed an important measure. It is in terms of new regulations to encourage industries to use equipment with low carbon emission and to implement the program of energy conservation and auditing.

\section{Energy Sector}

This sector is not optimistic enough as the targeted 2015 preparedness is only set at 4.00 on average, means that it only needs 0.41 point of improvement. It is reasonable then that capacity building is the only measure proposed for the human resource factor. For the institutional factor, the treatment proposed is also only one, i.e., improved coordination between related and responsible institutions with other stakeholders.

For the financial factor, this sector proposes two measures. The first, as found in many programs, is the need to increase provincial budget and to get help from investors. The second is the need for support from local governmental budgets, which is found only in the program for facilitating and coordinating the development of local and rural energy.

Meanwhile, various treatments are there for the physical and equipment factor, from improving the auditing equipment to gaining the investors' help in constructing the bio-fuel production plants. However, they are essentially of one kind; that is to improve the availability of buildings and equipment both quantitatively and qualitatively. It is similar to that in the industry sector.

Finally, there is no measure proposed for the legal framework factor.

\section{Agriculture Sector}

The agriculture sector only needs around 0.2 point of improvement for the 2015 preparedness; however, necessary treatments are there.

For the human resource factor, the treatment proposed is only one, i.e., increasing the quantity and quality of the personnel through new recruitment and capacity buildings. Similarly, there is also only one measure for the institutional factor. It is to improve coordination and cooperation with other governmental institutions of various levels and with other stakeholders, including related communities and the private sector.

Meanwhile, for the financial factor, the main measure is to get funding help from various sources. Among them are additional provincial budget, the national budget, the related local governmental budgets and the private 
sector. As for the physical and equipment factor, the treatment is to improve the availability of equipment quantitatively and qualitatively. Finally, for the legal framework factor, only in the program for controlling the use of chemical fertilizers that treatment is needed, i.e., to improve supervision for better law enforcement.

\section{Transportation Sector}

This sector is optimistic enough, with about one point of improvement targeted for 2015. For the human resource factor, the first measure is to increase the number of personnel as found, for example, in the program of trees planting on street kerbsides. The second one is to improve the quality of personnel, as in the programs of developing Intelligent Transport System (ITS) and implementing traffic impact control system.

For the institutional factor, treatments proposed in some programs are of one kind, i.e., the need of institutional strengthening. It would need further elaboration to be applicable. Meanwhile, for the financial factor, many programs need the commitment of funding from the CJPG, as in the programs of developing ITS and implementing traffic impact control system. Another measure is to get funding help from external sources, as in the program of road construction and maintenance.

About the physical and equipment factor, the main treatment is to improve the quantity and quality of equipment, as proposed in many programs. Interestingly, this sector also proposes improvement in supervision of the implementation of the program of trees planting on street kerbsides. It is, perhaps, the need to provide supervision work with sufficient equipment. Another interesting measure is to prepare a non-motorized transport plan, which reveals the need to refine the existing spatial plans of regencies and cities in Central Java.

Finally, for the legal framework factor, this sector proposes many new provincial regulations because many programs would need them, for example, the programs of developing ITS and parking management.

\section{Waste Management Sector}

The waste management sector needs a 0.4 point of improvement for 2015. For the human resource, this sector proposes one measure, i.e., to improve the quality of personnel and other involving stakeholders.

For the institutional factor, there are two kinds of treatments. The first is to improve the capacity of the implementing institutions, for example, in the programs of developing sanitary landfill system and controlled landfill system for the final waste disposal sites. The other one is to develop collaboration with the private sector and related communities, as in the programs of developing integrated waste Treatment Plants (TPST) and developing biogas from small scale industries.
About the financial factor, to increase funding from the provincial, national and local governmental budgets is the main treatment proposed in many programs. Only two programs need different treatment. The programs of plastic waste recycling and developing biogas from small scale industries need help from the private sector. However, two programs need both treatments, i.e., the programs of developing TPST and community institutional strengthening for waste management.

Meanwhile, increasing the quantity of equipment and updating the technology are the main measures for the physical and equipment factor. All programs need the treatments. The program of developing TPST, for example, needs additional transporters, computers, weight measurements and garbage destroying tools.

Finally, for the legal framework factor, better law enforcement is the sole measure proposed in many programs.

\section{Forestry Sector}

Although practically no improvement is targeted for 2015 preparedness of this sector, proposed measures are there. For the human resource factor, the treatment is to improve the quantity and quality of personnel through recruitment and trainings. It is there in practically all programs. However, in some programs, the treatment includes trainings for other stakeholders, like the communities, as in the programs of rehabilitating critical land in the priority DAS, implementing horticulture technology and crop enrichment.

Similarly, for the institutional factor, the treatment proposed is only one, i.e., to improve coordination among the implementing institutions. A sole treatment is also there for the financial factor, which is to increase funding from the provincial budget. Meanwhile, for the factor of physical and equipment, this sector proposes to improve the quantity and quality of equipment. Finally, for the legal framework factor, all involving institutions had better have the same perception about the regulations of the implementation. It is there in practically all programs, with an additional treatment for the program of rehabilitating critical land in the priority DAS, i.e., improving the supervision work.

\section{Limitations}

This study experienced four limitations. First, in the process of interview, some interviewees only had limited time available. It has made the inquiries could not be answered more deeply. Fortunately, this problem could be resolved in the workshop. Information unobtainable from the interviews was finally completed from the workshop.

Second, not all of the interviewees could attend the workshop. Three of them could not participate due to 
various reasons. Providentially, representatives of their institutions were there in the workshop. This problem had been anticipated though. For this reason, measures were taken, i.e., inviting representatives from the extended key institutions, conducting a half day-pre-workshop-meeting and giving a longer introduction section in the workshop. These were very helpful to get all the participants accustomed with the workshop purposes.

Third, some cells in the filled forms have been left blank. It is somewhat irritating, especially for scoring purposes. However, this flaw is understandable when the interview results are considered. As the RADGRK drafting process was somewhat in a hurry, a considerable amount of the programs planned is apparently not within the authority of the CJPG. So, it is difficult for the CJPG stakeholders to make estimations.

Finally, there is some inconsistency of the workshop participants in filling in the forms. It is apparent, for example, in some of the targeted scores for 2015 preparedness that are lower, although only very tiny, than those of the existing situation, especially in the forestry sector. Nevertheless, it is just a minor flaw because the stakeholders have still proposed reasonable treatments for better implementation.

\section{Conclusion}

This study has answered important inquiries about the preparedness of the Central Java Provincial Government for RAD-GRK implementation. First, in general, the preparedness level of the CJPG is 3.47 out of 5.0. It means that the provincial government is somewhat better than half prepared and so it certainly needs help and adjustment to implement the RAD-GRK successfully. However, if each of the six sectors is considered, the industry sector needs more attention than the others as this sector is the least prepared. Among the other sectors, differences in preparedness are there but not too much.

Second, when considering each of the five factors influencing the CJPG preparedness, no significant differences are there on average. However, the factors of human resource and physical and equipment could be given priority for the distance from fully prepared is, on average, the farthest (1.60). More importantly in the industry sector, the human resource and institutional factors need to be prioritized because the scores are very low (1.00 each). It should then be followed by the physical and equipment factor (2.00), the financial factor (3.00) and the legal framework factor (blank) consecutively.

Third, although the CJPG is a kind of moderate in targeting for 2015 preparedness improvement, the proposed measures are quite reasonable. Many of the measures are common in nature and thus in accordance with those recommended in the related literature. However, some of the measures proposed in many related studies have not come up in this study. Two reasons may be the cause, i.e., the difference between adaptation and mitigation focus and the difference in characteristics of the key persons and respondents involved. At last, some of the measures need more elaboration to be applicable, but many of them, as far as the proposing institutions' intentions are concerned, are executable.

\section{Acknowledgement}

The author would like to convey much gratefulness to the GIZ Indonesia for the opportunity given as a consultant in the study of Assessing the Readiness of RAD-GRK Implementation in Central Java Province in 2013. This paper presents a part of the study, which concepts and methods were proposed and executed by the author. Much gratitude is especially conveyed to $\mathrm{Mr}$. Moh. Nurhadi, Heiner von Luepke, Phillip Munzinger and David Pangaribuan of GIZ, who have given valuable supports and comments during the study. The author is also thankful to Ms. Mega Anggraeni and Ms. Renni Nur Hayati for their useful assistance.

\section{Ethics}

This research, as standard in all GIZ Indonesia projects involving humans, has obtained an ethical clearance from the Central Java Provincial Government.

\section{References}

Ahamed, M., 2013. Community based approach for reducing vulnerability to natural hazards (cyclone, storm surges) in coastal belt of Bangladesh. Proc. Environ. Sci., 17: 361-371. DOI: 10.1016/j.proenv.2013.02.049

Anguelovski, I., E. Chu and J. Carmin, 2014. Variations in approaches to urban climate adaptation: Experiences and experimentation from the global South. Global Environ. Change, 27: 156-167. DOI: 10.1016/j.gloenvcha.2014.05.010

Arvidsson, M., C.R. Johansson, A. Ek and R. Akselsson, 2006. Organizational climate in air traffic control: Innovative preparedness for implementation of new technology and organizational development in a rule governed organization. Applied Ergonom., 37: 119-129. DOI: 10.1016/j.apergo.2005.06.005

Arvidsson, V., J. Holmström and K. Lyytinen, 2014. Information systems use as strategy practice: A multi-dimensional view of strategic information system implementation and use. J. Strategic Inform. Syst., 23: 45-61. DOI: 10.1016/j.jsis.2014.01.004 
Biagini, B., R. Bierbaum, M. Stults, S Dobardzic and S.M. McNeeley, 2014. A typology of adaptation actions: A global look at climate adaptation actions financed through the global environment facility. Global Environ. Change 25: 97-108. DOI: $10.1016 /$ j.gloenvcha.2014.01.003

Bihari, M. and R. Ryan, 2012. Influence of social capital on community preparedness for wildfires. Landscape Urban Plann., 106: 253-261.

DOI: 10.1016/j.landurbplan.2012.03.011

Casey, M.M., W.R. Payne and R.M. Eime, 2012. Organisational readiness and capacity building strategies of sporting organisations to promote health. Sport Manage. Rev., 15: 109-124.

DOI: 10.1016/j.smr.2011.01.001

Chowdhury, P.D., C.E. Haque and G. Smith, 2011. A critical review of climate change induced psychosocial impacts and options for strengthening social support systems. Am. J. Environ. Sci., 7: 316-330. DOI: 10.3844/ajessp.2011.316.330

Creswell, J.W., 2009. Research Design: Qualitative, Quantitative and Mixed Methods Approaches. 1st Edn., Sage Publications, Thousand Oaks, ISBN-10: 1412965578, pp: 260.

Lehman, W.E.K., J.M. Greener and D.D. Simpson, 2002. Assessing organizational readiness for change. Elsevier J. Substance Abuse Treatment, 22: 197-209. DOI: 10.1016/S0740-5472(02)00233-7, PMID: 12072164

Lwasa, S., 2010. Adapting urban areas in Africa to climate change: The case of Kampala. Curr. Opin. Environ. Sustainability, 2: 166-171. DOI: $10.1016 /$ j.cosust.2010.06.009

Majra, J.P. and D. Acharya, 2009. Protecting health from climate change: Preparedness of medical interns. Ind. J. Community Medicine, 34: 317-320. DOI: $10.4103 / 0970-0218.58390$

Patil, R.P. and T.M. Deepa, 2007. Climate change: The challenges for public health preparedness and response-an Indian case study. Ind. J. Occupat. Environ. Medicine, 11: 113-115.

DOI: $10.4103 / 0019-5278.38460$

CJPG, 2012. Rencana Aksi Daerah Penurunan Emisi Gas Rumah Kaca (RAD-GRK) Provinsi Jawa Tengah 2010-2020 (Regional Action Plan to Reduce GHG Emissions of the Central Java Province 2010-2020). Pemprov. Jateng, Semarang.

CJPG, 2014. Rencana Pembangunan Jangka Menengah Daerah (RPJMD) Provinsi Jawa Tengah 2013-2018 (Mid-term Regional Development Plan of the Central Java Province 2013-2018). Semarang: Pemprov. Jateng.
PRI, 2011. Presidential Decree No. 61/2011 Regarding National Action Plan for Reducing GHG Emissions (RAN-GRK). Presiden RI.

Prior, T. and C. Eriksen, 2013. Wildfire preparedness, community cohesion and social-ecological systems. Global Environ. Change, 23: 1575-1586. DOI: 10.1016/j.gloenvcha.2013.09.016

Ramsay, T., 2004. Identifying the un-researched factor in disaster management: Spiritual preparedness. Int. J. Humanit., 2: 1099-1110.

Rodriguez, D., H. Cox, P. deVoil and B. Power, 2014. A participatory whole farm modelling approach to understand impacts and increase preparedness to climate change in Australia. Agric. Syst., 126: 50-61. DOI: 10.1016/j.agsy.2013.04.003

Stone, R.C., 2014. Constructing a framework for national drought policy: The way forward-the way Australia developed and implemented the national drought policy. Weather Climate Extremes, 3: 117-125. DOI: $10.1016 /$ j.wace.2014.02.001

Storch, S. and G. Winkel, 2013. Coupling climate change and forest policy: A multiple streams analysis of two German case studies. Forest Policy Econom., 36: 14-26. DOI: 10.1016/j.forpol.2013.01.009

Sugiri, A., 2009. Redressing Equity Issues in Natural Resource-Rich Regions: A Theoretical Framework for Sustaining Development in East Kalimantan, Indonesia. In: Environmental Ethics: Sustainability and Education, Weber, E. (Ed.), Inter-Disciplinary Press, Oxford, ISBN-13: 978-1-904710-74-5, pp: 107-135.

Sugiri, A. and N. Nuraini 2013. Towards equity-based regional development: Addressing spatial inequality in the Blitar region. Int. J. Civic, Political Community Stud., 10: 91-109.

Travis, W.R., 2013. Design of a severe climate change early warning system. Weather Climate Extremes, 2: 31-38. DOI: $10.1016 /$ j.wace.2013.10.006

Valkila, N. and A. Saari 2012. Consumer panel on the readiness of Finns to behave in a more proenvironmental manner. Sustainability J., 4: 1561-1579. DOI: $10.3390 /$ su4071561

van Aalst, M.K., T. Cannon and I. Burton, 2007. Community level adaptation to climate change: The potential role of participatory community risk assessment. Global Environ. Change, 18: 165-179. DOI: 10.1016/j.gloenvcha.2007.06.002 